\title{
Women's empowerment in agriculture and child nutritional status in rural Nepal
}

\author{
Kenda Cunningham ${ }^{1, *}$, George B Ploubidis ${ }^{1}$, Purnima Menon ${ }^{2}$, Marie Ruel $^{3}$, \\ Suneetha Kadiyala ${ }^{1}$, Ricardo Uauy ${ }^{1,4}$ and Elaine Ferguson ${ }^{1}$ \\ 'Department of Population Health, Faculty of Epidemiology, London School of Hygiene and Tropical Medicine, \\ Keppel Street, London WC1E 7HT, UK: ${ }^{2}$ Poverty Health and Nutrition Division, International Food Policy Research \\ Institute, New Delhi, India: ${ }^{3}$ Poverty Health and Nutrition Division, International Food Policy Research Institute, \\ Washington, DC, USA: ${ }^{4}$ Institute of Food Nutrition and Food Technology (INTA), Santiago, Chile
}

Submitted 2 March 2014: Final revision received 22 January 2015: Accepted 28 January 2015: First published online 23 March 2015

\begin{abstract}
Objective: To examine the association between women's empowerment in agriculture and nutritional status among children under 2 years of age in rural Nepal. Design: Cross-sectional survey of 4080 households conducted in 2012. Data collected included: child and maternal anthropometric measurements; child age and sex; maternal age, education, occupation and empowerment in agriculture; and household size, number of children, religion, caste and agro-ecological zone. Associations between the Women's Empowerment in Agriculture Index (WEAI)'s Five Domains of Empowerment (5DE) sub-index and its ten component indicators and child length-for-age $Z$-scores (LAZ) and weight-for-length $Z$-scores (WLZ) were estimated, using ordinary least-squares regression models, with and without adjustments for key child, maternal and household level covariates.

Setting: Two hundred and forty rural communities across sixteen districts of Nepal. Subjects: Children under 24 months of age and their mothers ( $n$ 1787).

Results: The overall WEAI 5DE was positively associated with LAZ $(\beta=0 \cdot 20$, $P=0 \cdot 04)$. Three component indicators were also positively associated with LAZ: satisfaction with leisure time $(\beta=0 \cdot 27, P<0 \cdot 01)$, access to and decisions regarding credit $(\beta=0 \cdot 20, P=0.02)$ and autonomy in production $(\beta=0 \cdot 10, P=0 \cdot 04)$. No indicator of women's empowerment in agriculture was associated with WLZ.

Conclusions: Women's empowerment in agriculture, as measured by the WEAI $5 \mathrm{DE}$ and three of its ten component indicators, was significantly associated with LAZ, highlighting the potential role of women's empowerment in improving child nutrition in Nepal. Additional studies are needed to determine whether interventions to improve women's empowerment will improve child nutrition.
\end{abstract}

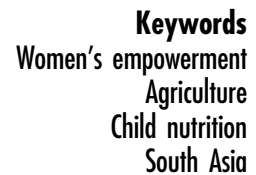

Nearly half of all children under 5 years of age in South Asia are undernourished ${ }^{(1-3)}$. The high prevalence of childhood undernutrition relative to other low- and middle-income countries is concerning, especially given South Asia's recent economic gains ${ }^{(4-6)}$. Women's particularly low social status and disempowerment in this region, compared with other regions, create barriers to social development and result in severe consequences for child health and nutrition, including intra-uterine growth retardation, low birth weight and suboptimal child $\operatorname{growth}^{(4,6-8)}$.

Greater maternal decision making, control and autonomy in the household likely improve child nutrition by improving child-care practices ${ }^{(8,9)}$. Some empirical studies have found women's status and empowerment to be associated with child height/length-for-age (HAZ/LAZ), weight-for-age (WAZ) or weight-for-height/length (WHZ/ WLZ) $Z$-scores in South Asia. However, the number of studies is limited and their findings are inconsistent ${ }^{(10-21)}$. This may reflect inter-study differences in population characteristics, study settings or indicators of women's empowerment used, in addition to real differences in the importance of women's empowerment for child nutrition in different settings ${ }^{(8,14,22-24)}$.

Kabeer's definition of empowerment as 'the expansion in people's ability to make strategic life choices in a context where this ability was previously denied to them' is the most frequently referenced ${ }^{(25)}$. However, definitions, indicators and methods used to measure women's empowerment vary across studies. These inconsistencies 
present challenges in interpreting the evidence base ${ }^{(25-27)}$. Measurements such as age at marriage and level of education inherently provide only limited and indirect information regarding an individual's autonomy, control or power. These types of measurements generally reflect prior investments made into girls rather than a mother's current level of empowerment. Aggregate indices, increasingly used in women's empowerment studies, usually capture decision making and autonomy but fail to assess other dimensions of women's empowerment, such as workload and social support. To address these limitations and to standardize the terminology and domains included in defining and measuring women's empowerment, in 2011 the US Agency for International Development commissioned the creation of a new index: the Women's Empowerment in Agriculture Index (WEAI). The International Food Policy Research Institute and the Oxford Poverty and Human Development Initiative jointly created, piloted and validated the WEAI in Bangladesh, Guatemala and Uganda. This new index captures the multidimensional nature of empowerment in rural agrarian settings. It aims to facilitate measurement of constraints related to women's roles in agriculture and to enable assessment of the impact of agricultural and women's empowerment interventions on empowerment itself and a variety of other outcomes including agriculture production, women's own well-being and that of their children ${ }^{(27)}$. However, evidence relating the index to health and nutrition outcomes is only beginning to emerge ${ }^{(28)}$, with no published studies having yet explored the association between the WEAI and child nutrition.

The level of undernutrition among Nepalese children under 5 years of age is among the highest in the world: $41 \%$ of children are stunted, $11 \%$ are wasted and $29 \%$ are underweight ${ }^{(29)}$. Despite the decline in agricultural employment since 2006, agriculture remains the primary occupation and source of income in Nepal: more than three out of every four households engage in agricultural activities; about $90 \%$ of women engage in agricultural production activities; and women perform $70 \%$ of livestock-related labour. The heavy reliance on agriculture, for both food consumption and income generation, and the large contribution made by women to agriculture mean that gender roles and women's empowerment in agricultural activities may be important determinants of child health and nutrition in $\mathrm{Nepal}^{(30-33)}$.

In the present study, we use the WEAI to specifically test the association of various indicators of women's empowerment in agriculture (specifically, maternal empowerment, because all women sampled in the study were mothers of the children included in the study) with child nutritional status in rural Nepal. Our two main outcomes are child LAZ, a measure of chronic undernutrition, and WLZ, an indicator of acute energy deficiency; both indicators could be affected by women's empowerment through effects on child feeding, health seeking and/or hygiene practices and other factors such as maternal time allocation and decisionmaking power. The overall aims of the current paper are to: (i) assess the extent to which women's empowerment in agriculture is associated with the anthropometric indicators in children under 2 years of age residing in rural Nepal; and (ii) determine whether the direction and strength of association differ by indicator of women's empowerment in agriculture.

\section{Methods}

\section{Survey design and sampling}

We used data from a baseline cross-sectional survey of an evaluation of Suaahara, a multi-sectoral maternal and child health and nutrition intervention funded by the US Agency for International Development. The survey was conducted in sixteen districts of Nepal from mid-June to early October (the rainy season) of 2012. Households were selected to participate in the survey using multistage cluster sampling. Districts, which were the primary sampling units, were purposively selected into two groups: eight Suaahara intervention districts and eight comparison districts matched based on their similarities with intervention districts related to social, economic and agroecological characteristics. Using probability-proportionalto-size techniques we randomly selected five rural village development committees within each district and three rural wards within each village development committee. Finally, in each ward, we listed all households with a child aged $<5$ years and randomly selected seventeen of these households. When more than one child aged $<5$ years resided in the household, the index child was selected at random. In total, the sample included 4080 households across 240 wards.

For the present study, we restricted our analysis to households with an index child under 2 years of age ( $n$ 1787). The main reasons for this decision were twofold. First, most of the WEAI indicators reflect a woman's current empowerment in household agricultural activities and may not reflect her degree of empowerment 3-5 years ago, particularly in a context of high emigration of males. Second, most growth faltering occurs during the first 24 months of age, and thus current household characteristics including maternal empowerment are likely to be more closely associated with the recent process of growth faltering than past growth faltering ${ }^{(34,35)}$. Thus, an a priori decision was made to restrict our analyses to children aged $<2$ years.

Ethical approval was obtained from the International Food Policy Research Institute, the Nepal Health Research Council and the London School of Hygiene and Tropical Medicine. All respondents gave their informed verbal consent to survey participation.

\section{Anthropometric assessment}

Duplicate measurements of maternal and child weight and height (supine length of children) were taken using 
standardized calibrated digital weighing scales (Seca GmbH \& Co. KG, model 881 1021659; precision $\pm 100 \mathrm{~g}$ ) and height/length boards (ShorrBoard produced by Weight and Measure LLC; precision $\pm 0.1 \mathrm{~cm}$ ). Child age was derived from maternal recall or, when available, from a birth certificate ( $n 874 ; 49 \%$ of children aged $<2$ years).

LAZ and WLZ were computed using the WHO growth reference standards. Children with length-for-age or weight-for-length below -2 SD from the median of the reference population ( $\mathrm{LAZ}<-2$ or $\mathrm{WLZ}<-2$ ) were classified as stunted or wasted, respectively ${ }^{(34,36-38)}$.

\section{Child, maternal and housebold characteristics}

For the survey, trained enumerators ( $n 70)$ conducted two household interviews, one with the mother of the index child and one with a major household decision maker, who was the husband of the interviewed mother (27\%), or when unavailable, another male household decision maker (34\%). When no males were available in the household, another female household decision maker was selected (39\%). Questionnaires were extensively field tested, revised, translated and back-translated to ensure data quality. During the maternal interviews, data were collected on maternal knowledge, attitudes and practices regarding: child health, child care, infant and young child feeding, and hygiene behaviours. Additional data were collected on: maternal and child food consumption in the previous $24 \mathrm{~h}$, household food security, maternal use of health services, and access to and use of water and sanitation facilities. In interviews of the household decision maker, topics included: household composition, asset ownership and agricultural practices. All interviews also involved spot check observations to assess household construction and water, sanitation and hygiene facilities and practices. Furthermore, a series of survey questions originally developed for the WEAI were asked in both household interviews; these questions covered five domains related to household agricultural activities: production, resources, income, leadership and time use. For households that did not include a residing man and where a woman answered the household decision-maker questionnaire, the series of WEAI questions was only asked once, during the mother's interview.

The WEAI is an aggregate weighted sum of two subindices: the Five Domains of Empowerment (5DE) index accounts for $90 \%$ of the full WEAI and the Gender Parity Index (GPI) accounts for the remaining 10\%. The 5DE aggregate index is comprised of ten component binary indicators. For each indicator, a woman is classified as empowered or not based on a minimum threshold specific to that dimension of the index. The 5DE then uses a nested weighting structure in which each of the ten indicators is weighted equally within its domain and, in turn, the five domains are weighted equally. The aggregate 5DE uses the weighted indicators and classifies an individual as empowered overall or not (binary) if the individual has adequate achievements in $80 \%$ of the weighted component indicators (see online supplementary material, Supplemental Table 1). Additional details regarding index construction and validation are available elsewhere ${ }^{(27,28,39)}$.

In the present study, we used only the $5 \mathrm{DE}$ instead of the full WEAI $(5 \mathrm{DE}+\mathrm{GPI})$ because the 5DE relies exclusively on the maternal interviews. Constructing the GPI requires dual-adult (male-female) households, which were not available in $41 \%$ of the surveyed households because of high levels of male emigration. Thus, in the current paper we present results for eleven binary indicators of women's empowerment in agriculture: one aggregate $5 \mathrm{DE}$ binary indicator and ten component binary indicators. As noted above, the overall aggregate 5DE indicator measures empowerment in $80 \%$ of any combination of the weighted ten component indicators; each component indicator is defined in the same way as in the original 5DE (Table 1).

\section{Statistical analysis}

Statistical analyses were done using the Stata statistical software package release 13 (2013). Children not measured or with anthropometric $Z$-score values outside the biologically plausible range (LAZ $<-6 />6$ and WLZ $<-5 />5 ; n 11$ and $n 26$, respectively) were excluded from analysis, as recommended by the $\mathrm{WHO}^{(36,37)}$. No $\log$ transformations were necessary because all $Z$-scores were normally distributed. Some households were also excluded from our analysis because construction of the mother's 5DE was not possible due to her lack of engagement in agricultural activities or missing data ( $n$ 473). Therefore, of the original 1787 households with children aged $<2$ years included in the survey, 1306 households were included for analysis with LAZ and 1294 households were included for analysis with WLZ.

The associations between each of the eleven indicators of women's empowerment in agriculture and child LAZ and WLZ were tested using ordinary least-squares bivariate and multivariate regression analyses, controlling for district-level clustering. For each of these linear regressions, the dependent variable was the $Z$-score and the independent variables were the dichotomous empowerment variables. In the multivariate ordinary least-squares regressions we also adjusted for various child, maternal and household factors that could confound the relationship between women's empowerment in agriculture and child nutritional status based on a literature review of similar studies and our knowledge of the local context ${ }^{(6,10-21)}$. We included child sex and age; maternal age, height and highest level of formal schooling completed (none or less than one year, some primary, completed primary (grade 5), some secondary, or completed secondary (grade 10) or higher); and household number of children aged $<5$ years (one or more than one), agro-ecological zone of residency (mountains, hills or terai) and wealth status. To capture wealth, an asset index was constructed as the sum of household ownership of livestock 
Table 1 Five Domains of Empowerment: indicator definitions

\begin{tabular}{|c|c|c|}
\hline Domain & Indicator & Definition of empowerment \\
\hline \multirow[t]{2}{*}{ Production } & Input into productive decisions & $\begin{array}{l}\text { A mother with at least some input into decisions, makes the decisions or feels she } \\
\text { could make the decisions if she wanted, in at least two agricultural production } \\
\text { domains }\end{array}$ \\
\hline & Autonomy in production & $\begin{array}{l}\text { A mother who does not strongly disagree that her decisions related to at least one } \\
\text { of agricultural production, taking crops to the market or livestock raising were } \\
\text { externally motivated or coerced }\end{array}$ \\
\hline \multirow[t]{3}{*}{ Resources } & Ownership of assets & A mother who solely or jointly owns at least one large or two small assets \\
\hline & $\begin{array}{l}\text { Right to purchase, sell or transfer } \\
\text { agricultural assets }\end{array}$ & $\begin{array}{l}\text { A mother who has at least one joint right to purchase, sell or transfer at least one } \\
\text { large or two small household agricultural assets }\end{array}$ \\
\hline & Access to and decisions on credit & $\begin{array}{l}\text { A mother who has at least one source of formal or informal credit and makes at } \\
\text { least one decision solely or jointly for at least one of these types of household } \\
\text { credit }\end{array}$ \\
\hline Income & Control over use of income & $\begin{array}{l}\text { A mother with at least some input into decisions about income generated from } \\
\text { household agricultural activities or feels she can make decisions in at least one } \\
\text { major household income/expenditure domain }\end{array}$ \\
\hline \multirow[t]{2}{*}{ Leadership } & Group membership & A mother who participates in at least one community group \\
\hline & Speaking in public & $\begin{array}{l}\text { A mother who has any degree of comfort when speaking in public in at least one of } \\
\text { the three contexts asked about }\end{array}$ \\
\hline \multirow[t]{2}{*}{ Time } & Workload & $\begin{array}{l}\text { A mother who works no more than } 10.5 \mathrm{~h} / \mathrm{d} \text { including work as an employee; } \\
\text { self-employed; in agricultural labour; and domestic work }\end{array}$ \\
\hline & Leisure & $\begin{array}{l}\text { A mother who does not express any dissatisfaction with the amount of time she has } \\
\text { available for leisure activities }\end{array}$ \\
\hline
\end{tabular}

types, small assets, large assets and productive agricultural assets. For all analyses, associations were considered statistically significant if the $P$ value was $\leq 0 \cdot 05$.

Finally, we tested two-way interactions with factors which we had hypothesized a priori could potentially modify the association between women's empowerment in agriculture and child nutritional status. Specific interactions assessed were between the overall 5DE and child sex, child age, maternal education, maternal age, household wealth status, caste, agro-ecological zone, and whether agriculture is the mother's primary or secondary occupation or not.

\section{Results}

\section{Participant characteristics}

Table 2 presents key descriptive statistics of the study participants, for the whole sample as well as by inclusion status to facilitate comparison of households included in our analyses with households excluded from our analyses.

For the whole sample, the mean age of children was 12 months and the percentages of boys and girls in the sample were the same. The mean age of mothers was 25 years and $32 \%$ of them had no formal education or less than one year of schooling. Among the surveyed mothers, 79\% reported agriculture as their primary or secondary occupation and while $47 \%$ were from upper caste groups, $20 \%$ were Dalit, i.e. the lowest caste group in Nepal. Half of the households resided in the hills and about one quarter each in the mountains and the terai areas. Among these households, 35\% had more than one child ( $<5$ years) and the average household size was six members.

The mean LAZ was -1.42 and the mean WLZ was -0.89 . Approximately one-third of children were classified as stunted and just over one in six children were classified as wasted.
Less than $10 \%$ of mothers were defined as empowered in agriculture, according to the 5DE. Among the ten component indicators included in the $5 \mathrm{DE}$, the highest percentages of maternal empowerment were found in asset ownership (85\%), satisfaction with amount of time available for leisure activities (83\%), being comfortable speaking up in public (80\%) and input into production decisions (79\%). The lowest levels of empowerment related to indicators of group membership (21\%), access to and decision making on credit (30\%), autonomy in production decisions (31\%) and workloads greater than $10 \cdot 5 \mathrm{~h} / \mathrm{d}$ (38\%).

Descriptive analyses reveal that excluded households were similar to those included in the study on a number of key variables including child LAZ and WLZ, maternal height, number of children aged $<5$ years residing in the household, caste and agro-ecological zone of residency. However, we did find significant differences for some sociodemographic characteristics for households included in the analyses $v$. those excluded from the analyses. The mothers from excluded households were older (by an average of 1.6 years, $P<0.001$ ) than the mothers from included households. Children from excluded households were slightly older (by about a month, $P=0 \cdot 04$ ) and they came from households that were smaller (by about two members, $P<0 \cdot 001$ ) and wealthier (owned on average two more assets than included households, $P<0 \cdot 001)$ than children from included households.

\section{Women's empowerment in agriculture and child antbropometry}

Table 3 shows results from the bivariate analyses between child, maternal and household characteristics, including women's empowerment in agriculture, and child LAZ. Mean child LAZ was significantly associated with the following characteristics: child age, child sex, maternal height, maternal 
Table 2 Child, maternal and household characteristics of the sample, by 5DE inclusion status; children under 24 months of age and their mothers $(n$ 1787) from 240 rural communities across sixteen districts of Nepal, mid-June to early October 2012

\begin{tabular}{|c|c|c|c|c|c|c|c|c|c|c|}
\hline \multirow[b]{2}{*}{ Variable } & \multicolumn{3}{|c|}{ All } & \multicolumn{3}{|c|}{ Included } & \multicolumn{3}{|c|}{ Excluded } & \multirow[b]{2}{*}{$P$ value } \\
\hline & $n$ & $\begin{array}{c}\text { Mean } \\
\text { or } \%\end{array}$ & SD & $n$ & $\begin{array}{c}\text { Mean } \\
\text { or } \%\end{array}$ & SD & $n$ & $\begin{array}{c}\text { Mean } \\
\text { or } \%\end{array}$ & SD & \\
\hline \multicolumn{11}{|l|}{ Child characteristics } \\
\hline Age (months) & 1787 & $12 \cdot 3$ & 6.7 & 1307 & $12 \cdot 1$ & $6 \cdot 7$ & 480 & $12 \cdot 9$ & $6 \cdot 8$ & 0.04 \\
\hline Age group (\%) & 1787 & & & 1307 & & & 480 & & & 0.22 \\
\hline $0-5.9$ months & & 21.5 & & & $22 \cdot 6$ & & & $18 \cdot 8$ & & \\
\hline $6-11.9$ months & & $26 \cdot 9$ & & & $27 \cdot 2$ & & & $26 \cdot 2$ & & \\
\hline $12-17.9$ months & & $26 \cdot 7$ & & & 26.9 & & & $26 \cdot 0$ & & \\
\hline $18-23.9$ months & & 24.9 & & & $22 \cdot 3$ & & & $29 \cdot 0$ & & \\
\hline Sex: boys (\%) & 1787 & 50.7 & & 1307 & $51 \cdot 2$ & & 480 & 49.4 & & 0.52 \\
\hline \multicolumn{11}{|l|}{ Anthropometric Z-scores } \\
\hline Length-for-age Z-score & 1776 & -1.42 & 1.30 & 1307 & -1.41 & 1.33 & 469 & -1.46 & 1.29 & 0.65 \\
\hline Stunting prevalence (\%) & 1776 & $32 \cdot 3$ & & 1307 & $32 \cdot 5$ & & 469 & $31 \cdot 8$ & & 0.81 \\
\hline Weight-for-length Z-score & 1761 & -0.89 & $1 \cdot 10$ & 1295 & -0.87 & $1 \cdot 12$ & 466 & -0.96 & 1.13 & $0 \cdot 18$ \\
\hline Wasting prevalence (\%) & 1761 & $15 \cdot 2$ & & 1295 & $14 \cdot 3$ & & 466 & $17 \cdot 6$ & & $0 \cdot 12$ \\
\hline \multicolumn{11}{|l|}{ Maternal characteristics } \\
\hline Height $(\mathrm{cm})$ & 1786 & $151 \cdot 6$ & 5.5 & 1307 & $151 \cdot 7$ & 5.5 & 480 & $151 \cdot 3$ & $5 \cdot 4$ & 0.23 \\
\hline Age (years) (range: 15-52) & 1787 & 24.9 & $5 \cdot 6$ & 1307 & 24.5 & 5.5 & 480 & $26 \cdot 1$ & $5 \cdot 7$ & $<0.001$ \\
\hline Years of education & 1786 & $5 \cdot 2$ & 4.6 & 1306 & 5.4 & 4.6 & 480 & 4.7 & 4.4 & 0.05 \\
\hline Level of formal schooling (\%) & 1786 & & & 1306 & & & 480 & & & 0.95 \\
\hline Less than grade 1 & & 31.9 & & & $30 \cdot 7$ & & & $35 \cdot 2$ & & \\
\hline Some primary & & 13.7 & & & $13 \cdot 0$ & & & $15 \cdot 4$ & & \\
\hline Completed primary (grades $1-5$ ) & & $7 \cdot 7$ & & & $7 \cdot 8$ & & & 7.5 & & \\
\hline Some secondary & & $25 \cdot 4$ & & & $25 \cdot 8$ & & & $24 \cdot 2$ & & \\
\hline Completed secondary (grades $6-10$ ) & & $10 \cdot 9$ & & & $11 \cdot 0$ & & & $10 \cdot 4$ & & \\
\hline Completed grade 12 or higher & & 10.5 & & & $11 \cdot 7$ & & & $7 \cdot 3$ & & \\
\hline Agricultural occupation (primary or secondary) (\%) & 1787 & $79 \cdot 2$ & & 1307 & $82 \cdot 6$ & & 480 & 69.7 & & $<0.001$ \\
\hline Women's empowerment in agriculture* $(\%)$ & & & & 1307 & & & & & & \\
\hline Overall WEAI 5DE: empowered & & & & & $9 \cdot 2$ & & & & & \\
\hline Input into production decisions: empowered & & & & & $79 \cdot 2$ & & & & & \\
\hline Autonomy in production: empowered & & & & & 31.2 & & & & & \\
\hline Ownership of assets: empowered & & & & & $84 \cdot 6$ & & & & & \\
\hline Right to purchase, sell or transfer agricultural assets: empowered & & & & & $56 \cdot 9$ & & & & & \\
\hline Access to and decisions on credit: empowered & & & & & $30 \cdot 1$ & & & & & \\
\hline Control over use of income: empowered & & & & & $59 \cdot 3$ & & & & & \\
\hline Group membership: empowered & & & & & $21 \cdot 0$ & & & & & \\
\hline Speaking in public: empowered & & & & & 79.5 & & & & & \\
\hline Workload ( $<10.5 \mathrm{~h} / \mathrm{d}$ paid/unpaid labour): empowered & & & & & $38 \cdot 1$ & & & & & \\
\hline Leisure (satisfaction with time): empowered & & & & & 83.4 & & & & & \\
\hline \multicolumn{11}{|l|}{ Household characteristics } \\
\hline Religion: Hinduism (\%) & 1787 & $91 \cdot 1$ & & 1307 & $91 \cdot 1$ & & 480 & $91 \cdot 0$ & & 0.87 \\
\hline Caste (\%) & 1787 & & & 1307 & & & 480 & & & 0.56 \\
\hline Upper caste groups & & $46 \cdot 7$ & & & $49 \cdot 0$ & & & $40 \cdot 2$ & & \\
\hline Relatively advantaged Janajatis & & 6.4 & & & $6 \cdot 4$ & & & $6 \cdot 3$ & & \\
\hline Religious minorities \& disadvantaged non-Dalit terai & & 4.6 & & & 4.3 & & & 5.4 & & \\
\hline Disadvantaged Janajatis & & $22 \cdot 9$ & & & $23 \cdot 1$ & & & $22 \cdot 3$ & & \\
\hline Dalit & & 19.5 & & & $17 \cdot 1$ & & & $25 \cdot 8$ & & \\
\hline Wealth (range of $0-23$ assets) & 1787 & 8.5 & 3.5 & 1307 & 9.0 & 3.5 & 480 & 7.3 & 3.3 & $<0.001$ \\
\hline Agro-ecological zone of residence (\%) & 1787 & & & 1307 & & & 480 & & & 0.11 \\
\hline Mountains & & $25 \cdot 1$ & & & $27 \cdot 4$ & & & $18 \cdot 8$ & & \\
\hline Hills & & $50 \cdot 6$ & & & $49 \cdot 3$ & & & 54.4 & & \\
\hline Terai & & $24 \cdot 3$ & & & 23.3 & & & $26 \cdot 9$ & & \\
\hline Household size & 1787 & $5 \cdot 7$ & 2.4 & 1307 & $6 \cdot 2$ & $2 \cdot 3$ & 480 & 4.4 & $2 \cdot 0$ & $<0.001$ \\
\hline More than one child aged $<5$ years $(\%)$ & 1787 & 35.4 & & 1307 & $36 \cdot 3$ & & 480 & $32 \cdot 9$ & & 0.15 \\
\hline
\end{tabular}

5DE, Five Domains of Empowerment; WEAl, Women's Empowerment in Agriculture Index.

${ }^{*}$ All women's empowerment in agriculture percentages represent a binary variable constructed based on the aggregation cut-off levels explained for each indicator in Table 1. The empowerment in the overall WEAI 5DE percentage represents an individual who, based on these indicator level cut-offs, is empowered in some combination of the weighted indicators reflecting at least $80 \%$ total adequacy.

age, maternal education, maternal agricultural occupation, household caste, household wealth state, agro-ecological zone of residence and number of children aged $<5$ years in the household. Mean child LAZ was also significantly associated with the overall 5DE and the following dimensions of women's empowerment in agriculture: control over use of income, being comfortable speaking in public and satisfaction with time available for leisure activities. There was no significant association between child LAZ and the remaining seven dimensions of women's empowerment in agriculture 
Table 3 Bivariate associations* between child, maternal and household characteristics and LAZ among children 0-24 months of age ( $n$ 1306) from 240 rural communities across sixteen districts of Nepal, mid-June to early October 2012

\begin{tabular}{|c|c|c|c|c|}
\hline & \multirow[b]{2}{*}{$n$} & \multicolumn{2}{|c|}{ LAZ } & \multirow[b]{2}{*}{$P$ value } \\
\hline & & Mean & SD & \\
\hline \multicolumn{4}{|l|}{ Child's age group } & $<0.001$ \\
\hline $0-5.9$ months & 294 & -0.60 & 0.11 & \\
\hline $6-11.9$ months & 355 & $-1 \cdot 18$ & 0.13 & \\
\hline $12-17.9$ months & 352 & -1.75 & 0.11 & \\
\hline 18-23.9 months & 305 & $-2 \cdot 06$ & $0 \cdot 10$ & \\
\hline \multicolumn{4}{|l|}{ Child sex } & 0.02 \\
\hline Boys & 669 & -1.47 & 0.10 & \\
\hline Girls & 637 & -1.35 & 0.13 & \\
\hline \multicolumn{4}{|l|}{ Maternal height } & $<0.001$ \\
\hline$<148 \mathrm{~cm}$ & 322 & -1.80 & 0.12 & \\
\hline$\geq 148 \mathrm{~cm}$ & 984 & $-1 \cdot 28$ & 0.12 & \\
\hline \multicolumn{4}{|l|}{ Maternal age } & $<0.001$ \\
\hline$<19$ years & 184 & $-1 \cdot 31$ & 0.12 & \\
\hline $20-29$ years & 914 & -1.37 & 0.12 & \\
\hline $30-39$ years & 184 & -1.65 & 0.11 & \\
\hline $40-49$ years & 22 & -2.06 & 0.30 & \\
\hline$\geq 50$ years & 2 & $-2 \cdot 88$ & 0.01 & \\
\hline \multicolumn{4}{|l|}{ Maternal schooling } & $<0.001$ \\
\hline Less than grade 1 & 401 & -1.86 & 0.09 & \\
\hline Some primary & 170 & -1.48 & 0.09 & \\
\hline Completed primary (grades $1-5$ ) & 102 & -1.53 & 0.12 & \\
\hline Some secondary & 337 & $-1 \cdot 18$ & 0.08 & \\
\hline Completed secondary (grades $6-10$ ) & 144 & -1.04 & 0.15 & \\
\hline Completed grade 12 or higher & 152 & -0.96 & 0.18 & \\
\hline \multicolumn{4}{|l|}{ Maternal agricultural occupation (primary or secondary) } & $<0.001$ \\
\hline Yes & 1079 & -1.51 & 0.11 & \\
\hline No & 227 & -0.96 & 0.13 & \\
\hline \multicolumn{5}{|l|}{ Maternal empowerment in agriculture } \\
\hline Overall WEAI 5DE: empowered & 120 & -1.09 & 0.09 & $<0.001$ \\
\hline Overall WEAI 5DE: disempowered & 1186 & -1.44 & 0.11 & \\
\hline Input into production decisions: empowered & 1035 & -1.44 & 0.11 & 0.33 \\
\hline Input into production decisions: disempowered & 271 & -1.32 & 0.17 & \\
\hline Autonomy in production: empowered & 406 & -1.31 & 0.17 & 0.22 \\
\hline Autonomy in production: disempowered & 900 & -1.46 & $0 \cdot 10$ & \\
\hline Ownership of assets: empowered & 1105 & -1.39 & 0.13 & 0.37 \\
\hline Ownership of assets: disempowered & 201 & -1.54 & 0.13 & \\
\hline Right to purchase, sell or transfer agricultural assets: empowered & 744 & -1.45 & 0.11 & 0.44 \\
\hline Right to purchase, sell or transfer agricultural assets: disempowered & 562 & $-1 \cdot 36$ & 0.14 & \\
\hline Access to and decisions on credit: empowered & 392 & -1.32 & 0.12 & 0.09 \\
\hline Access to and decisions on credit: disempowered & 914 & -1.45 & 0.11 & \\
\hline Control over use of income: empowered & 776 & -1.31 & 0.11 & $<0.001$ \\
\hline Control over use of income: disempowered & 530 & -1.56 & 0.11 & \\
\hline Group membership: empowered & 273 & -1.33 & 0.16 & 0.36 \\
\hline Group membership: disempowered & 1033 & -1.43 & 0.11 & \\
\hline Speaking in public: empowered & 1038 & -1.34 & 0.10 & 0.02 \\
\hline Speaking in public: disempowered & 268 & -1.66 & 0.16 & \\
\hline Workload ( $<10.5 \mathrm{~h} / \mathrm{d}$ paid/unpaid labour): empowered & 497 & -1.30 & 0.13 & 0.07 \\
\hline Workload ( $<10.5 \mathrm{~h} / \mathrm{d}$ paid/unpaid labour): disempowered & 809 & -1.48 & 0.11 & \\
\hline Leisure (satisfaction with time): empowered & 1090 & -1.34 & $0 \cdot 10$ & $<0.001$ \\
\hline Leisure (satisfaction with time): disempowered & 216 & -1.79 & 0.15 & \\
\hline \multicolumn{4}{|l|}{ Household religion } & 0.51 \\
\hline Hinduism & 1190 & -1.42 & 0.12 & \\
\hline Other & 116 & -1.31 & 0.16 & \\
\hline \multicolumn{4}{|l|}{ Household caste } & $<0.001$ \\
\hline Upper caste groups & 641 & -1.41 & 0.16 & \\
\hline Relatively advantaged Janajatis & 84 & -0.93 & 0.21 & \\
\hline Religious minorities \& disadvantaged non-Dalit terai & 56 & -1.67 & 0.14 & \\
\hline Disadvantaged Janajatis & 301 & -1.33 & 0.08 & \\
\hline Dalit & 224 & -1.65 & 0.13 & \\
\hline \multicolumn{4}{|l|}{ Household wealth quintiles } & $<0.001$ \\
\hline Lowest & 235 & -1.79 & 0.10 & \\
\hline Second & 257 & -1.61 & 0.13 & \\
\hline Third & 281 & -1.44 & 0.15 & \\
\hline Fourth & 294 & -1.36 & 0.12 & \\
\hline Fifth & 239 & -0.86 & 0.18 & \\
\hline
\end{tabular}




\begin{tabular}{|c|c|c|c|c|}
\hline & \multicolumn{3}{|c|}{ LAZ } & \multirow[b]{2}{*}{$P$ value } \\
\hline & $n$ & Mean & SD & \\
\hline Household agro-ecological zone of residence & & & & 0.04 \\
\hline Mountains & 358 & -1.83 & 0.20 & \\
\hline Hills & 643 & $-1 \cdot 29$ & 0.10 & \\
\hline Terai & 305 & $-1 \cdot 18$ & 0.26 & \\
\hline Household size & & & & 0.10 \\
\hline $1-6$ members & 793 & $-1 \cdot 36$ & 0.12 & \\
\hline 7 or more members & 513 & -1.50 & 0.11 & \\
\hline Household number of children aged $<5$ years & & & & 0.04 \\
\hline One & 831 & $-1 \cdot 35$ & 0.12 & \\
\hline Two or more & 475 & -1.51 & 0.11 & \\
\hline
\end{tabular}

LAZ, length-for-age Z-score; WEAI, Women's Empowerment in Agriculture Index; 5DE, Five Domains of Empowerment.

${ }^{*}$ In this table, these bivariate associations control only for district-level clustering.

Table 4 Multivariate associations* between women's empowerment in agriculture (measured by the WEAI 5DE) and LAZ among children 0-24 months of age ( $n$ 1306) from 240 rural communities across sixteen districts of Nepal, mid-June to early October 2012

\begin{tabular}{lrr}
\hline & & LAZ \\
\cline { 2 - 3 } & \multicolumn{1}{c}{3} & $95 \% \mathrm{Cl}$ \\
\hline Overall WEAI 5DE: empowered & 0.20 & $0.01,0.38$ \\
Dimensions of women's empowerment in agriculture & 0.12 & $-0.06,0.30$ \\
Input into productive decisions: empowered & 0.10 & $0.01,0.20$ \\
Autonomy in production decisions: empowered & 0.01 & $-0.34,0.36$ \\
Ownership of assets: empowered & -0.02 & $-0.16,0.12$ \\
Right to purchase, sell or transfer agricultural assets: empowered & 0.20 & $0.04,0.35$ \\
Access to and decision-making power regarding credit: empowered & 0.13 & $-0.03,0.29$ \\
Control over use of income: empowered & 0.07 & $-0.12,0.26$ \\
Group membership: empowered & 0.06 & $-0.11,0.23$ \\
Comfortable speaking in public: empowered & -0.06 & $-0.22,0.11$ \\
Workload (<10.5/d paid/unpaid labour): empowered & 0.27 & $0.12,0.42$ \\
Satisfaction with time for leisure activities: empowered & 0.42 \\
\hline
\end{tabular}

WEAI, Women's Empowerment in Agriculture Index; 5DE, Five Domains of Empowerment, LAZ, length-for-age Z-score.

*In this table, each row represents the results of a separate regression analysis for each indicator of the WEAI 5DE and its association with child length-for-age $Z$-score. In the full models, we control for district-level clustering; child sex and age; maternal age, height and education; and household wealth status, number of children aged $<5$ years and agro-ecological zone of residence. Each woman's empowerment indicator is binary: not empowered $=0$ and empowered $=1$.

or between child LAZ and maternal agricultural engagement, household religion, household caste or household size. Similar bivariate analyses between child, maternal and household characteristics, including women's empowerment in agriculture, and child WLZ was also done (see online supplementary material, Supplemental Table 2).

Table 4 shows the multivariate analyses between eleven indicators of women's empowerment in agriculture, as measured by the overall WEAI 5DE and its ten component indicators, and child LAZ. After adjusting for child, maternal and household characteristics, the positive association between the 5DE and LAZ $(\beta=0 \cdot 20,95 \%$ CI $0 \cdot 01,0 \cdot 38)$ remained significant, albeit attenuated. Results from multivariate analyses of the 5DE component indicators showed three of the ten dimensions of women's empowerment in agriculture were significantly associated with LAZ: (i) autonomy in production $(\beta=0 \cdot 10,95 \%$ CI $0 \cdot 01,0 \cdot 20$ ); (ii) access to and decision-making power regarding credit $(\beta=0.20,95 \%$ CI $0.04,0.35)$; and (iii) maternal satisfaction regarding the amount of time she has available for leisure activities $(\beta=0 \cdot 27,95 \%$ CI $0 \cdot 12$, $0 \cdot 42$ ). The remaining seven indicators (input into household production decisions; asset ownership; ability to purchase, sell or transfer household assets; control over income; group membership; being comfortable speaking up in public; workload $<10.5 \mathrm{~h}$ in a $24 \mathrm{~h}$ period) were not significantly associated with LAZ.

Neither the overall 5DE nor any of its ten component indicators was associated with WLZ (see online supplementary material, Supplemental Table 3). Furthermore, none of the interactions hypothesized were significant. Hence, none of these results are presented.

\section{Discussion}

The present study used the 5DE sub-index of the WEAI to measure women's empowerment, a complex, multidimensional construct, and showed that women's empowerment in agriculture was significantly associated 
with LAZ in children aged $<2$ years in rural Nepal. In addition to this association, three of the ten component indicators of the 5DE were also positively associated with child LAZ: autonomy in production decisions, satisfaction with time available for leisure activities, and access to and decision making regarding credit.

By contrast, none of the indicators of women's empowerment in agriculture were associated with WLZ. These results confirm findings from recent literature reviews, which show inconsistent findings related to associations between selected measures of women's empowerment and indicators of child nutritional status ${ }^{(40,41)}$. The specific indicators used for both women's empowerment and child nutritional status may be partly responsible for some of the inconsistencies found in the literature. In our study, the lack of association between the acute measure of child nutritional status (WLZ) and different domains of women's empowerment in agriculture suggests that other environmental or household-level factors such as high rates of infections, severe poverty and/or food insecurity may be driving such high levels of wasting in this setting. Without access to some of the most basic resources (water, sanitation, health services, income), it is possible that women's empowerment is simply not enough to prevent acute child undernutrition.

The present study is the first one to examine the association of women's empowerment in agriculture and child nutritional status in South Asia. In the study we took advantage of a recently developed tool available for measuring women's empowerment in agriculture: the WEAI. The key strengths of the WEAI are that it: (i) is the first and only survey-based tool specifically designed to measure women's empowerment in agriculture; (ii) explicitly recognizes the multidimensionality of empowerment; and (iii) includes both a composite index and disaggregated indicators, which allow for a deeper understanding of the relative contributions of different dimensions of (dis)empowerment in a particular context.

Greater household decision-making power among women generally fosters improvements in child health and nutrition ${ }^{(42)}$; some South Asian studies have shown this positive association $^{(10,11,13-15)}$. In Nepal, maternal input into household decision making has been found to be positively associated with child $\operatorname{HAZ}^{(12,13,15,20)}$, but the relationship has varied by decision-making domain, such as large $v$. small household purchases, and by nutritional indicators measured ${ }^{(16)}$. The $5 \mathrm{DE}$ includes two indicators within its household agricultural production domain: (i) sole or joint input in production decisions; and (ii) autonomy related to production decisions ${ }^{(42,43)}$. In our study, input into household production decisions was not associated with LAZ, but autonomy in production was positively associated with LAZ. These results show that the extent to which a woman's motivation for agricultural decision making was autonomous ( $v$. controlled), and not merely her having had input into productive decisions, was important for translating her participation in agricultural production activities into nutritional benefits for her child ${ }^{(43)}$

Neither of the two asset indicators - (i) ownership of major household assets or (ii) decision making over buying, selling or transferring owned productive assets - was associated with child anthropometry, but access to and decision-making power regarding household credit was associated with LAZ. To our knowledge no other study has explored the relationship between maternal decisionmaking power regarding household credit and child nutritional status in South Asia. The positive association found in our study between women's decision-making power regarding credit and child nutritional status may reflect that these women are more able to make decisions regarding accessing public services or that this additional financial resource enabled them to engage in seeking medical care or acquiring nutritious foods.

Sole or joint control over income and expenditures was not associated with child anthropometry in the present study, once wealth status was controlled for. This suggests that while lack of income and financial resources may be barriers to child growth, a woman's control over the use of income may not be a key barrier, or that high levels of poverty may attenuate its influence, in rural Nepal.

Previous studies have noted that greater control of resources by women can result in positive child outcomes ${ }^{(33,44)}$, but these studies have focused on decisionmaking autonomy for certain types of household expenditures, without differentiating by original source of the resource (assets, credit and income), as done in the 5DE. For example, several South Asian studies have grouped decisions on large and daily household purchases into an aggregate household decision-making index; findings from these studies on the associations with child nutritional status have been mixed ${ }^{(10,14,15)}$. A 2009 study found that mothers in Andhra Pradesh with the ability to set money aside had lower odds of their child being stunted than mothers without this particular type of financial autonomy ${ }^{(13)}$, whereas a later study using the same data set but constructing a composite financial autonomy index found no association between financial autonomy and LAZ, WAZ or WLZ ${ }^{(12)}$. A study in Nepal found an overall lack of association between maternal financial decision making and HAZ; a positive association between maternal control of daily household purchases and WHZ; and a negative association between her control of large household purchases and $\mathrm{WHZ}^{(16)}$. While these studies have addressed women's control of resources, comparison with our study was not possible because the $5 \mathrm{DE}$ differentiates decision making by type of financial resources (assets, credit and income). Our findings suggest that financial resources may be a prerequisite to acting on one's decision-making ability; perhaps neither owning a major asset nor decision-making power over that asset is sufficient to overcome resource constraints and allow 
translation into child nutritional well-being ${ }^{(43)}$. The disparate findings across studies suggest a complex set of relationships between women's control of resources (both absolute levels and types of resources) and child nutritional well-being in South Asia, which may differ by context, age of children, specific resource analysed, and the indicators and analytical methods used.

Neither leadership indicator - (i) membership in community groups or (ii) being comfortable speaking up in public - was associated with child LAZ in the present study, but these dimensions of women's empowerment are not expected to directly relate to child nutrition. In fact, even though community engagement could theoretically increase one's social status or access to information, it could also take time away from child-care activities. Some prior studies, however, noted that specific aspects of a woman's social network composition or her broader social capital may be important for child growth ${ }^{(17,19,45)}$. One study in India found that larger and more literate social networks were positively associated with LAZ, but greater proportions of non-family members in a mother's social network were negatively associated with $\mathrm{LAZ}^{(19)}$. Our findings were consistent with findings from a study in Andhra Pradesh reporting no association between maternal community group membership and LAZ among 6- to 18-month-old children ${ }^{(17)}$.

Lastly, the 5DE time domain is comprised of two indicators: (i) workload and (ii) satisfaction with the amount of time available for leisure activities. Although time devoted to work may influence child nutritional status, as optimal child-care practices are time intensive, no prior study has investigated this hypothesis in a South Asian setting. Similarly, little is known about satisfaction with leisure time and its relationship with child nutritional status in South Asia. In our study, we found no association between workload and child LAZ. However, maternal satisfaction with leisure time was positively associated with LAZ. This finding suggests that independent of the number of hours spent on work, a mother's perception regarding whether or not she has free time may be important for child nutrition. Perhaps perception of and satisfaction with free time reflect a woman's agency, lack of stress and mental well-being, which in turn can influence her child caregiving and feeding attitudes and practices and, in turn, child growth ${ }^{(46-48)}$.

Maternal education and height were also found to be determinants of young child nutritional status in our study. Maternal height captures genetic factors as well as longterm well-being (or deprivation); and education reflects long-term investments in girls and women. Both small stature and lack of education in women perpetuate the inter-generational transmission of poor nutrition. These more general, longer-term gender inequalities were associated with child nutrition in our study, which is consistent with prior studies ${ }^{(17,19,48,49)}$.

The present study has a few limitations. First, its crosssectional nature means that direction and causality of effects are uncertain. Second, the findings may not be fully generalizable because the survey was conducted during the rainy season and seasonality is known to influence agricultural production, income, food consumption, and health and nutritional status. Third, unknown and unmeasured (or imperfectly measured) confounding factors may also affect the results. Despite these limitations, the study is the first to examine these dynamics in South Asia and is therefore valuable to generate new hypotheses and a deeper understanding of how women's empowerment in agriculture may be associated with child nutrition in rural Nepal. The large sample size, high quality control measures used during data collection and the comprehensive set of child, maternal and household-level variables controlled for in this set of analyses generate confidence that the results are robust.

The WEAI suffers from limitations typical of aggregate/ composite indices as well as limitations related to an index that is designed to enable cross-country comparisons. Although designed for each indicator to contribute to the aggregate measurement in the same way, some dimensions of empowerment may be so context specific that some indicators may reflect different phenomena in different settings. Additional adaptation research and validation of the WEAI across different contexts is ongoing and will help to continue refining and enhancing the tool's usefulness and comparability across contexts. This index reflects women's empowerment in one domain, that of agriculture, rather than overall empowerment. Thus, the results are limited to agricultural households and may not be generalizable to all Nepalese households. However, in the context of rural Nepal, which is heavily agrarian and with women doing most of the agricultural labour, a specific focus on empowerment related to household agricultural practices is particularly useful for future programme and policy development. Finally, gender parity and negotiations between women and men are important elements of women's empowerment; in the present study we were unable to look at these household dynamics because of the high levels of male emigration and the resulting low proportion of dual-adult (malefemale) households in the survey.

\section{Future research and policy implications}

In summary, our study provides empirical evidence that some aspects of women's empowerment in agriculture are associated with young child nutritional status in rural Nepal. Based on our results, researchers, programmers and policy makers working on improving child nutrition in Nepal should pay particular attention to specific dimensions of women's empowerment in agriculture such as autonomy in production decisions, access to and decisionmaking control regarding household credit and satisfaction with the amount of leisure time available. Given that our study does not confirm causality, further research is needed to test the gains in child nutrition that can be 
achieved by targeted interventions aimed at improving these specific aspects of women's empowerment in agriculture in Nepal. Additional research is also needed to: (i) determine whether the relationships between women's empowerment in agriculture and child nutritional status found in rural Nepal are also found in other South Asian contexts; (ii) disentangle the relationship between women's empowerment in agriculture and women's empowerment more broadly in the same population and setting; and (iii) understand the pathways and mechanisms through which women's empowerment in agriculture influences child nutritional status in Nepal.

The Government of Nepal recognizes that health and nutrition play an integral role in national development and that addressing the country's persistent problem of poor health and nutrition will require investments across multiple sectors. Nepal's recent Multi-sectoral Nutrition Plan explicitly recognizes the multi-causal aetiology of child undernutrition and promotes coordination and collaboration across institutions and sectors including education, health, agriculture, and water and sanitation ${ }^{(50)}$. These formal acknowledgements of the necessity for action across sectors, and the Government of Nepal's focus on rights-based inclusiveness and gender equity, to tackle the diverse and more structural determinants of child undernutrition are promising. Based on our findings, Nepal's policies and plans to implement programmes that support social inclusion and the empowerment of women are an important step in the right direction. Addressing longer-term structural causes of poor child growth, such as women's disempowerment, may be challenging given deeply rooted socio-cultural norms. However, given the heavily agrarian nature of Nepal's economy and the fact that nearly all women in rural Nepal are engaged in agricultural activities, our findings suggest that empowering women in agriculture should be a priority both for women's own social status and well-being and to improve the nutritional status of future generations of Nepalese children.

\section{Acknowledgements}

Acknowledgements: The authors gratefully acknowledge the cooperation of the institutions that assisted in designing and implementing the survey: New ERA and Suaabara partners. They also acknowledge financial support from the Leverhulme Center for Integrative Research on Agriculture and Health (LCIRAH) and from the CGIAR Research Program on Agriculture for Nutrition and Health (A4NH), led by the International Food Policy Research Institute (IFPRI). They are also grateful for the intellectual guidance provided by IFPRI colleagues including Hazel Malapit, Agnes Quisumbing, Wahid Quabili and Parul Tyagi. They are thankful to Suaahara staff including Lynn Lederer, Kirk Dearden, Ravindra Thapa and Pooja Pandey, as well as Nira Joshi and the entire New ERA Suaahara team, for their generous collaboration on data collection. Finally, the authors acknowledge the thousands of female community health volunteers and study participants, who made possible this research. Financial support: Suaahara, funded by the US Agency for International Development (USAID) and managed by Save the Children-Nepal, funded the present survey. This study is made possible by the generous support of the American people through USAID. The contents are the responsibility of K.C. and CO-authors and do not necessarily reflect the views of USAID or the US Government. Conflict of interest: None. Authorship: K.C. contributed to study design and questionnaire development, facilitated fieldwork including data collection and management, developed research questions, conducted statistical analysis, and drafted and revised the manuscript. G.B.P., E.F. and R.U. provided guidance in defining the conceptual framework and guiding data analysis. S.K. was IFPRI's Principal Investigator for this survey; she contributed to study design and questionnaire development and supervised data collection and management. P.M. and M.R. led the overall impact evaluation design, and contributed to baseline survey design, questionnaire development and data analysis. All authors contributed to research question development, reviewed and edited manuscript drafts, and read and approved the final manuscript. Ethics of human subject participation: IFPRI, the Nepal Health Research Council and the London School of Hygiene and Tropical Medicine approved the study. All respondents gave their informed verbal consent to survey participation.

\section{Supplementary material}

To view supplementary material for this article, please visit http://dx.doi.org/10.1017/S1368980015000683

\section{References}

1. Black RE, Alderman H, Bhutta ZA et al. (2013) Maternal and child nutrition: building momentum for impact. Lancet $\mathbf{3 8 2}$, $13-15$.

2. Gulati JK (2010) Child malnutrition: trends and issues. Anthropologist 12, 131-140.

3. Stevens GA, Finucane MM, Paciorek CJ et al. (2012) Trends in mild, moderate, and severe stunting and underweight, and progress towards MDG 1 in 141 developing countries: a systematic analysis of population representative data. Lancet 380, 824-834.

4. Ramalingaswami V, Jonsson U \& Rohde J (1996) Commentary: The Asian Enigma. New York: UNICEF; available at http://www.unicef.org/pon96/nuenigma.htm

5. Haddad L, Peña C, Nishida C et al. (1996) Food Security and Nutrition Implications of Intrahousehold Bias: A Review of Literature. FCND Discussion Paper no. 19. Washington, DC: IFPRI; available at http://www.ifpri.org/publication/foodsecurity-and-nutrition-implications-intrahousehold-bias

6. Smith LC, Ramakrishnan U, Ndiaye A et al. (2003) The Importance of Women's Status for Child Nutrition in Developing Countries. Research Report no. 131. Washington, DC: IFPRI; available at http://www.ifpri.org/sites/default/ files/publications/rr131.pdf 
7. Haddad L (1999) Women's status: levels, determinants, consequences for malnutrition, interventions, and policy. Asian Dev Rev 17, 96-131.

8. Smith LC, Ramakrishnan U, Ndiaye A et al. (2003) The importance of women's status for child nutrition. Food Nutr Bull 24, 287-288.

9. Engle PL, Menon P \& Haddad L (1999) Care and nutrition: concepts and measurement. World Dev 27, 1309-1337.

10. Bose S (2011) The effect of women's status and community on the gender differential in children's nutrition in India. J Biosoc Sci 43, 513-533.

11. Sethuraman K, Lansdown R \& Sullivan K (2006) Women's empowerment and domestic violence: the role of sociocultural determinants in maternal and child undernutrition in tribal and rural communities in South India. Food Nutr Bull 27, 128-143.

12. Shroff MR, Griffiths PL, Suchindran C et al. (2011) Does maternal autonomy influence feeding practices and infant growth in rural India? Soc Sci Med 73, 447-455.

13. Shroff M, Griffiths P, Adair L et al. (2009) Maternal autonomy is inversely related to child stunting in Andhra Pradesh, India. Matern Child Nutr 5, 64-74.

14. Begum S \& Sen B (2009) Maternal health, child wellbeing and chronic poverty: does women's agency matter? Bangladesh Dev Stud 32, 69-93.

15. Desai S \& Johnson K (2005) Women's decision making and child health: familial and social hierarchies. In A Focus on Gender - Collected Papers on Gender Using DHS Data, pp. 55-68 [S Kishor, editor]. Calverton, MD: ORC Macro.

16. Dancer D \& Rammohan A (2009) Maternal autonomy and child nutrition: evidence from rural Nepal. Indian Growth Dev Rev 2, 18-38.

17. De Silva MJ \& Harpham T (2007) Maternal social capital and child nutritional status in four developing countries. Health Place 13, 341-355.

18. Mashal T, Takano T, Nakamura K et al. (2008) Factors associated with the health and nutritional status of children under 5 years of age in Afghanistan: family behaviour related to women and past experience of war-related hardships. BMC Public Health 8, 301.

19. Moestue H, Huttly S \& Sarella L (2007) 'The bigger the better' - mothers' social networks and child nutrition in Andhra Pradesh. Public Health Nutr 10, 1274-1282.

20. Brennan L, Mcdonald J \& Shlomowitz R (2004) Infant feeding practices and chronic child malnutrition in the Indian states of Karnataka and Uttar Pradesh. Econ Hum Biol 2, 139-158.

21. Aslam M \& Kingdon GG (2012) Parental education and child health - understanding the pathways of impact in Pakistan. World Dev 40, 2014-2032.

22. World Bank, Food and Agriculture Organization of the United Nations \& International Fund for Agricultural Development (2009) Gender in Agriculture Sourcebook. Washington, DC: International Bank for Reconstruction and Development.

23. Sraboni E, Malapit H \& Quisumbing A (2012) The Women's Empowerment in Agriculture Index for Bangladesh's Feed the Future Zone of Influence. Washington, DC: IFPRI.

24. Barrett CB, Carter MR \& Timmer CP (2010) A century-long perspective on agricultural development. Am J Agric Econ 92, 447-468.

25. Kabeer N (1999) Resources, agency, achievements: reflections on the measurement of women's empowerment. Dev Chang 30, 435-464.

26. Malhotra A, Schuler SR \& Boender C (2002) Measuring Women's Empowerment as a Variable in International Development. Background Paper Prepared for the World Bank Workshop on Poverty and Gender: New Perspectives. Washington, DC: World Bank; available at http://
siteresources.worldbank.org/INTGENDER/Resources/MalhotraSchulerBoender.pdf

27. US Agency for International Development, International Food Policy Research Institute \& Oxford Poverty and Human Development Initiative (2012) Women's Empowerment in Agriculture Index. Washington, DC: IFPRI; available at http:// www.ifpri.org/publication/womens-empowerment-agricultureindex

28. Sraboni E, Malapit HJ, Quisumbing AR et al. (2014) Women's empowerment in agriculture: what role for food security in Bangladesh? World Dev 61, 11-52.

29. Ministry of Health and Population, Government of Nepal, New ERA \& ICF International (2012) Nepal Demographic and Health Survey 2011. Kathmandu and Calverton, MD: MOHP, New ERA and ICF International; available at http:// dhsprogram.com/publications/publication-FR257-DHS-FinalReports.cfm

30. Paudel LM, ter Muelen U, Wollny C et al. (2009) Gender aspects in livestock farming: pertinent issues for sustainable livestock development in Nepal. Livest Res Rural Dev 21, 40 .

31. Miller BA (2011) The Gender and Social Dimensions to Livestock Keeping in South Asia: Implications for Animal Health Interventions. Edinburgh: GALVMed; available at http://r4d.dfid.gov.uk/PDF/Outputs/Galv/GALVmed-SouthAsian-Gender-Report.pdf

32. Tulachan P \& Batsa A (1994) Gender differences in livestock production management in the Chitwan district of Nepal. J Farming Syst Res 4, 121-135.

33. Quisumbing AR (2003) Household Decisions, Gender, and Development: A Synthesis of Recent Research. Washington, DC: IFPRI; available at http://www.ifpri.org/sites/default/ files/publications/genderbook.pdf

34. World Health Organization (1995) Physical Status: The Use and Interpretation of Anthropometry. Report of a WHO Expert Committee. WHO Technical Report Series no. 854. Geneva: WHO; available at http://www.who.int/childgrowth/publications/physical_status/en/

35. Ruel MT (2010) The Oriente study: program and policy impacts. J Nutr 140, 415-418.

36. Mei Z \& Grummer-Strawn LM (2007) Standard deviation of anthropometric $Z$-scores as a data quality assessment tool using the WHO growth standards: a cross country analysis. Bull World Health Organ 85, 441-448.

37. World Health Organization (2006) WHO Child Growth Standards: Length/Height-for-Age, Weight-for-Age, Weightfor-Length, Weight-for-Height and Body Mass Index-for-Age: Methods and Development. Geneva: WHO; available at http:// www.who.int/childgrowth/standards/technical_report/en/

38. WHO Multicentre Growth Reference Study Group (2006) WHO child growth standards based on length/height, weight and age. Acta Paediatr Suppl 405, 76-85.

39. Bhagowalia P, Menon P, Quisumbing AR et al. (2012) What Dimensions of Women's Empowerment Matter Most for Child Nutrition? Evidence using Nationally Representative Data from Bangladesh. IFPRI Discussion Paper no. 01192. Washington, DC: IFPRI; available at http://www.ifpri.org/ sites/default/files/publications/ifpridp01192.pdf

40. Cunningham K, Ruel M, Ferguson E et al. (2015) Women's empowerment and child nutritional status in South Asia: a synthesis of the literature. Matern Child Nutr 11, 1-19.

41. Carlson GJ, Kordas K \& Murray-Kolb LE (2014) Associations between women's autonomy and child nutritional status: a review of the literature. Matern Child Nutr (Epublication ahead of print version).

42. Vaz A, Alkire S, Quisumbing AR et al. (2013) Measuring Autonomy: Evidence from Bangladesh. Oxford: Oxford Poverty and Human Development Initiative; available at http://www. ophi.org.uk/wp-content/uploads/OPHI-RP38a2013.pdf?0a8fd7 
43. Alkire S, Meinzen-Dick R, Peterman A et al. (2013) The women's empowerment in agriculture index. World Dev $\mathbf{5 2}$, 71-91.

44. Yoong J, Rabinovich L \& Diepeveen S (2012) The Impact of Economic Resource Transfers to Women Versus Men: A Systematic Review. London: EPPI-Centre, Social Science Research Unit, Institute of Education, University of London.

45. Eklund P, Imai K \& Felloni F (2007) Women's organisations, maternal knowledge, and social capital to reduce prevalence of stunted children: evidence from rural Nepal. J Dev Stud 43, 456-489.

46. Patel V, Rahman A, Jacob KS et al. (2004) Effect of maternal mental health on infant growth in low income countries: new evidence from South Asia. BMJ 328, 820-823.

47. Ruel MT \& Alderman H (2013) Nutrition-sensitive interventions and programmes: how can they help to accelerate progress in improving maternal and child nutrition? Lancet 382, 536-551.

48. Rahman A, Iqbal Z, Bunn J et al. (2004) Impact of maternal depression on infant nutritional status and illness. Arch Gen Psychiatry 61, 946-952.

49. Rajaram S, Zottarelli LK \& Sunil TS (2007) Individual, household, programme and community effects on childhood malnutrition in rural India. Matern Child Nutr 3, $129-140$

50. Government of Nepal, National Planning Commission (2012) Multi-sectoral Nutrition Plan: For Accelerating the Reduction of Maternal and Child Under-nutrition in Nepal - Volume 1. Kathmandu: Government of Nepal, National Planning Commission; available at http://scalingupnutrition.org/wpcontent/uploads/2012/10/Neapl-MSNP-Volume-I-February2012_en.pdf 